Territorios 30 / Bogotá, 2014, pp. 17-38

ISSN: 0123-8418

ISSNe: 2215-7484

Reconfiguración territorial y mercados de tierras rurales

\title{
Agricultura familiar-Agronegocios: Disputas, interrelaciones y proyectos ${ }^{*}$
}

Family Farming-Agribusiness: Disputes, Relationships and Projects

Agricultura familiar-Agronegócios: Disputas, inter-relações e projetos

\section{Clara Craviotti ${ }^{\star \star}$}

Recibido: 24 de diciembre de 2013

Aprobado: 15 de marzo de 2014

Doi: dx.doi.org/10.12804/territ30.2014.01

Craviotti, C. (2014). Agricultura familiar-Agronegocios: disputas, interrelaciones y proyectos. Territorios, 30, 17-38. doi: dx.doi.org/10.12804/territ30.2014.01

\begin{abstract}
* Este artículo se enmarca en el PICT 1025 (2008), financiado por la Agencia Nacional de Promoción Cientifica y Tecnológica de Argentina. Las entrevistas fueron realizadas por la autora y por Paula Palacios, integrante del equipo de investigación.

** Doctora de la Universidad de Buenos Aires en Geografía. Máster en Ciencias Sociales con mención en Estudios Agrarios. FlacsoArgentina. Investigadora del Consejo Nacional de Investigaciones Cientificas y Técnicas (Conicet), Argentina. Correo electrónico: c.craviotti@conicet.gov.ar
\end{abstract}


Palabras clave

Modelos de desarrollo agrario, estructura agraria, conflictos territoriales, politicas agrarias.

Keywords

Models of agrarian development, agrarian structure, territorial conflicts, agrarian policies.

Palavras-chave

Modelos de desenvolvimento agrário, estrutura agrária, conflitos territoriais, políticas agrárias.

\section{territarias 30}

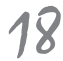

\section{RESUMEN}

Este artículo identifica aspectos donde emergen tensiones entre distintas formas de llevar a cabo la actividad agraria, sus impactos territoriales y las respuestas de los agentes sociales tanto desde el plano material como discursivo. Para ello analiza un partido de la región pampeana argentina donde tradicionalmente se han desarrollado producciones de trabajo-intensivas orientadas al mercado interno con participación de productores familiares, en el cual se constata la expansión de la agricultura extensiva orientada a los mercados mundiales. Frecuentemente considerada como ilustrativa del paradigma de los agronegocios, este tipo de agricultura se asocia a la gran escala, la búsqueda de beneficios de corto plazo y la creciente deslocalización del lugar de producción de aquel donde se invierten los excedentes obtenidos.

Si bien existen elementos que dan cuenta del afianzamiento del denominado modelo de los agronegocios en el territorio analizado, sus rasgos no se reproducen de manera mecánica y homogénea en el espacio rural. Existen situaciones híbridas y procesos no directamente atribuibles a la influencia que uno de ellos adquiere sobre el otro. Además, la importancia de los productores familiares y la índole de sus comportamientos productivos pueden representar posibles frenos a su expansión. No obstante, su debilidad como actores sociales para posicionar sus intereses constituye un indicador de sus dificultades para persistir dentro de la estructura agraria que se consolida.

\section{ABSTRACT}

This article identifies the aspects where tensions between different ways of carrying out the agricultural activity emerge, their local impacts and the responses of social agents both in material and discursive terms. It analyzes a district of the Argentinean Pampas region where traditionally labor intensive crops with participation of family farmers and oriented to the domestic market have developed, and in which there is a growing expansion of extensive agriculture oriented to world markets. Often regarded as an expression of the agribusiness paradigm, the latter is associated to large-scale agriculture seeking short-term benefits, and with the dislocation of production of the place where surpluses are invested.

While there are elements that reflect the consolidation of the so-called agribusiness model, its features are not reproduced mechanically and evenly in the rural space. There are hybrid situations and processes not directly attributed to the influence that one of them takes over the other. The importance of family farmers and the nature of their productive behavior may represent potential barriers to this. Nevertheless, their weakness as social actors to position their interests is an indicator of their difficulties to persist within the agrarian structure that is emerging.

\section{RESUMO}

Este artigo identifica aspectos onde emergem tensões entre diferentes firmas de levar a cabo a atividade agrária, seus impactos territoriais e as respostas dos agentes sociais tanto desde o plano material quanto o plano discursivo. Para isso analisa um partido da região pampeana argentina onde tradicionalmente têm se desenvolvido produções de trabalho intensivo orientadas ao mercado interno com participação de produtores familiares, no qual se constata a expansão da agricultura extensiva orientada aos mercados mundiais. Frequentemente considerada como ilustrativa do paradigma dos 
agronegócios, este tipo de agricultura associa-se à grande escala, a busca de benefícios de curto prazo e o crescente deslocamento do lugar de produção de aquele onde se invertem os excedentes obtidos.

Se bem existem elementos que dão conta da consolidação do denominado modelo dos agronegócios no território analisado, seus rasgos não se reproduzem de forma mecânica e homogênea no espaço rural. Existem situações híbridas e processos não diretamente atribuíveis à influência que um deles adquire sobre o outro. Além disso, a importância dos produtores familiares e a índole de seus comportamentos produtivos podem representar possíveis freios a sua expansão. Não obstante, sua debilidade como atores sociais para posicionar seus interesses constitui um indicador de suas dificuldades para persistir dentro da estrutura agrária que se consolida.

\section{Introducción}

Las transformaciones que se vienen produciendo en el agro argentino en las últimas décadas son objeto de controversias que traspasan las fronteras académicas, incluyendo a ámbitos estatales, organizaciones sociales y medios de comunicación. Adquieren visibilidad debido a la renovada importancia del agro en el desarrollo del país y a la capacidad que detentan algunas de sus entidades representativas para instalar sus visiones en la agenda pública.

Estos cambios se dan en el marco de una estructura agraria que supo ser menos polarizada que la de otros países latinoamericanos, con importante peso de los sectores medios. En efecto, el dualismo latifundio-minifundio no se instaló en Argentina como en otros países caracterizados por una base campesina más difundida y relaciones en parte asentadas en el patronazgo. A pesar de ello, ya en las primeras décadas del siglo Xx se delinea, en el caso de la región pampeana, la oposición entre la pequeña y mediana explotación agrícola (originada en procesos de colonización y arrendamiento) y la gran propiedad terrateniente (ganadera). Esta oposición fue diluyéndose con el transcurso de los años, llevando incluso a algunos autores a plantear la medianización de la estructura agraria de esta región (Barsky, 1992), ya sea por la conversión en farmers de estos pequeños productores agrícolas (conocidos localmente como chacareros), como por el fraccionamiento y modernización de las grandes propiedades.

Este tipo de productores familiares capitalizados también se desarrollaron en otras zonas del país, como el Alto Valle del Río Negro, algunas áreas de Chaco, Santiago del Estero y Misiones, donde lograron acceder a la propiedad de la tierra a través de políticas de colonización pública o privada. Pero se trataba de áreas particulares dentro de territorios más amplios donde los pequeños productores también estaban presentes, aunque asociados a condiciones de vida más precarias y situaciones problemáticas en materia de tenencia de la tierra. No obstante ello, una constante en la bibliografía fue remarcar las peculiaridades de este último sector en comparación con los campesinos de otros países latinoamericanos, entre otros la ausencia de pagos de territarias 30

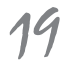


renta, la producción para el mercado (con un lugar secundario asignado a la producción para autoconsumo), la escasa diversificación, y una integración subordinada a complejos agroindustriales (Tsakoumagkos, 1987; Giarracca, 1990).

Sin embargo, un conjunto de estudios han dado cuenta de las mutaciones experimentadas en los últimos 20 años tanto por estos productores cercanos al nivel de subsistencia así como por los productores familiares capitalizados. Se trata de una etapa que coincide con la profundización de la globalización agroalimentaria y en el caso nacional, con la implementación de políticas neoliberales - con su combinación de apertura, desregulación y privatizaciones-, que se revierte parcialmente en el nuevo siglo con la recuperación de las capacidades estatales de regulación de los procesos económicos. Pero las tendencias perceptibles en los años ochenta no son fáciles de revertir y han dado lugar a una estructura agraria donde la agricultura empresarial se consolida. En el caso de los productores familiares pampeanos los cambios desde el punto de vista cuanti y cualitativo son de tal magnitud que inclusive han llevado a algunos autores a hacer hincapié en las limitaciones para la afirmación de una vía farmer de desarrollo agrario (Balsa, 2006). Por otra parte, y ampliando su influencia por fuera de los confines pampeanos, en la Argentina del siglo XXI parece reeditarse un nuevo dualismo, que opone a la agricultura familiar con los denominados agronegocios, en un proceso donde la expansión de estos se produciría a costa del desplazamiento de la primera.

Dada la polisemia de ambos conceptos, este artículo comienza planteando algunos ejes analíticos para delimitar sus significados en el contexto argentino. Luego se aborda un caso empírico donde la presencia de diferentes rasgos permite dar cuenta de la competencia entre modelos agrarios contrapuestos, pero también de situaciones híbridas y procesos no directamente atribuibles a la influencia que uno de ellos adquiere sobre el otro. Por último, se consideran las respuestas desplegadas por los actores desde el plano material y con respecto a proyectos de desarrollo, para terminar con el estudio de sus principales núcleos discursivos.

La idea central que guía el análisis es que existen soportes de índole material, organizativo y simbólico que hacen posible la expansión y persistencia de un determinado modelo agrario. En tal sentido, la permanencia de la agricultura familiar como tipo social no solo depende de las condiciones estructurales y los comportamientos adaptativos desplegados por estos agentes, sino también de la existencia o construcción de una coalición de actores comprometidos con su fortalecimiento. Desde esa perspectiva, los modelos que orientan las propuestas de intervención constituyen herramientas estratégicas en las manos de las instituciones o personas encargadas de la promoción del desarrollo.

En consecuencia, las representaciones predominantes en contextos concretos sobre el futuro del agro en su conjunto y

\section{territarias 30}


sobre la viabilidad de la agricultura familiar se traducirán en acciones (o por omisión, en la falta de estas) que incidirán sobre las condiciones de permanencia del sector (Mundler et ál, 2009), pudiendo contribuir a reforzar o contrarrestar los procesos de debilitamiento y exclusión que se dan en el plano estrictamente estructural.

\section{Agricultura familiar y agronegocios: multiplicidad de significados}

El concepto de agribusiness fue inicialmente desarrollado por Davis y Goldberg (1957) en Estados Unidos. En su versión original no solo enfatizaba los vínculos intersectoriales entre los agentes que se suceden a lo largo de una cadena agroalimentaria, sino que además ubicaba a la producción agropecuaria como parte de un sistema de mayor amplitud (Vértiz, 2013). Ya en ese entonces, los autores destacaban el carácter residual que progresivamente ocuparía la fase agraria, al externalizarse actividades hacia fuera de la explotación. ${ }^{1}$ El enfoque habría sufrido ajustes por parte del mismo Goldberg, quien lo amplió hacia la consideración de las instituciones que afectan las sucesivas fases, como los gobiernos, los mercados, las asociaciones comerciales (PAA, 2009). No obstante, al enfatizar las relaciones de interdependencia, asume la complementariedad entre las empresas capitalistas y los pequeños productores en relación a un producto determinado ( $\mathrm{Da}$ Silva, 1994). El aporte decisivo desde el punto de vista conceptual parece haber sido la nueva economía institucional, con eje en los costos de transacción y las estructuras de gobernanza o formas de coordinación (Wilkinson, 2008).

Estos aportes iniciales se pueden vincular con otros de inspiración francesa centrados en las cadenas (filières) y los trabajos de William Friedland (2001) sobre sistemas de mercancías (commodity systems analysis). En América Latina hubo también trabajos pioneros durante los años ochenta centrados en complejos agroindustriales. Pero a diferencia del enfoque de agronegocios interesado en lograr una mayor eficacia en la coordinación, estos trabajos pusieron énfasis en las características asimétricas de las relaciones entre los agentes, que, a su vez, influyen sobre la apropiación de excedentes (Teubal, 1999).

En el contexto latinoamericano más reciente, existen antecedentes que influyen en la actual adopción del término agronegocios y del enfoque subyacente. En este sentido se pueden mencionar organizaciones como la ABAG (Associaçao Brasileira de Agronegócios) o la académica PENSA (Programa de Estudos dos Negocios do Sistema Agroindustrial) de la Universidad de San Pablo. En ese contexto se ha señalado que el término tiene una intencionalidad política; legitimar la renovada presencia de la agricultura latifundista en ese país (Mançano Fernández, 2004). A pesar de ello subsistirían imprecisiones con relación a qué productos son parte del agronegocio o cuáles son las formas productivas que lo caracterizan. Inclusive algunas corrientes hablan del agronegocio 'patronal' por
'El agricultor moderno, decian Davis y Goldberg (1957), es un especialista que ve sus funciones reducidas a cultivar plantas y criar animales, habiendo sido transferidas en gran medida las demás actividades hacia fuera de la explotación, y sometidas a un proceso creciente de urbanización e industrialización (citado por Graziano da Silva, 1994). territarias 30 
contraposición al 'familiar'. Más decisivamente, los estudios realizados no permitirían visualizar claramente qué tipo de sociedad se construye en torno al agronegocio (Heredia Palmeira y Pereira Leite, 2010).

En el caso argentino, la difusión inicial del enfoque corrió por cuenta de Héctor Ordóñez (2000), quien retoma nociones de la economía institucional y su énfasis en la coordinación entre fases, y adopta el concepto de firma de Coase como nexo de contratos. El acento de este trabajo está puesto en el desarrollo de especialidades (un ejemplo serían los productos con denominación de origen) como alternativa a las producciones tradicionales. No obstante, trabajos posteriores (Bisang, 2007; Gras y Hernández, 2009; Reboratti, 2010), que aluden a la afirmación del modelo de los agronegocios para analizar los cambios de la agricultura argentina a partir de la década del noventa, ubican a commodities como la soja en el lugar central.

Se habla así de la expansión de una forma de producir orientada al aprovechamiento de oportunidades comerciales vinculadas a la exportación en el marco de una creciente inserción en circuitos globalizados, que pone énfasis en la rotación del capital y su desplazamiento de fijo a variable. Esto es posible debido a la recurrencia a formas flexibles de tenencia de la tierra y de realización del proceso productivo por medio de contratistas de servicios, donde el núcleo o empresa organizadora retiene para sí funciones clave como la coordinación y el acceso a fuentes de financiamiento. Una mayor intensidad en el uso de maquinaria e insumos de origen industrial sería asimismo central en tanto permite una mayor productividad, la disminución del costo laboral y la atenuación de la especificidad (biológica y climática) de la actividad agraria. Por último, la vinculación con el capital financiero para poder llevar a cabo proyectos a gran escala es otro componente presente en esta forma de encarar la actividad.

Desde el punto de vista simbólico se evoca también la conformación de una cierta cultura del agronegocio (Patrouilleau, Saavedra, Patroullieau y Gauna, 2012), que subraya la importancia de capacitarse e innovar y de los saberes especializados (agronómicos, pero sobre todo relacionados al manejo del negocio) por sobre los saberes transmitidos de generación en generación. Aunque sus mentores reconocen que este paradigma productivo genera perdedores, enfatizan que es capaz de articular intereses diversos. Desde una visión crítica, en cambio, se destaca que sus consecuencias son la exclusión de los productores familiares, la degradación ambiental y la creciente deslocalización del lugar donde se produce de aquel donde se invierten los excedentes obtenidos.

En el agro argentino, el referente empírico central de los agronegocios está constituido por el cultivo de soja, considerado como la síntesis y expresión más acabada del nuevo paradigma productivo. Ello obedece a varias razones: 1) En esta producción las innovaciones biotecnológicas (semillas transgénicas) marcaron un antes y después en el desarrollo del cultivo. 2) Su expansión territorial en la Argentina pone 
en cuestión tradicionales divisiones regionales de la actividad agraria. 3) Finalmente - pero no por ello menos importante- la soja presenta un carácter estratégico en la generación de divisas y en el financiamiento del gasto público argentino, ya que representa el $25 \%$ de las exportaciones.

Sin embargo, esta fascinación por el cultivo y por ciertos actores como los pools de siembra, en tanto encarnadura del modelo, ${ }^{2}$ ha llevado a que el análisis de hasta qué punto otras producciones se inscriben o conectan con los rasgos antes mencionados no haya sido emprendido con igual profundidad. Esta ausencia se nota especialmente cuando se trata de actividades agroindustriales que han conformado sistemas productivos locales que involucran diferentes etapas y agentes en el lugar donde se genera la materia prima.

En el otro polo de este nuevo dualismo está la 'agricultura familiar', término este que tiende a reemplazar a otros de uso previo en la Argentina como es el caso de 'pequeños productores'. Se trata de una categoría nacida de la mano de la interlocución con el Estado, ${ }^{3}$ pero al mismo tiempo es en una categoría en construcción, que es objeto de múltiples negociaciones en las que intervienen técnicos, administradores y organizaciones agrarias, además de científicos (Schiavoni, 2010). Así, según las percepciones de los diferentes actores, cubre una heterogeneidad de sujetos desde la agricultura campesina hasta la familiar capitalizada, caracterizados por el involucramiento del productor y su familia en las tareas y una inserción subordinada en los circuitos económicos, o bien únicamente a campesinos con fuertes componentes $\mathrm{co}^{-}$ munitarios y producción de autoconsumo y caracterizados por un acceso limitado a recursos más allá de la mano de obra familiar.

En este contexto de múltiples significados subyacentes, la polarización agricultura familiar-agronegocios que se está comenzando a instalar en ciertos ámbitos discursivos tiene, a nuestro juicio, la fortaleza y la debilidad de toda visión sintetizadora: fortaleza que radica en su capacidad de ilustrar ciertas tendencias destacadas de evolución de la actividad agroalimentaria; debilidad, al pasar por alto la heterogeneidad de situaciones existentes, que el desarrollo del capitalismo en el agro no ha logrado eliminar. Es decir, sin consideraciones ulteriores sobre qué engloban tanto los agronegocios como la agricultura familiar, las diversidades regionales y entre producciones pierden visibilidad, eludiéndose también el análisis de las formas de interacción y conflicto que existen entre ambas formas productivas. Un análisis en esta dirección es desarrollado en los apartados que siguen.

\section{Los espacios locales como campos de fuerzas}

El hecho de que en la Argentina el desarrollo de los agronegocios sea asociado a la expansión de producciones dirigidas al mercado internacional como es el caso de la soja no explica algunas cuestiones de gran importancia en el proceso de formación y reproducción de esta forma de producir. En
${ }^{2}$ Los pools de siembra consisten en arreglos organizacionales complejos para el desarrollo de la agricultura en gran escala, donde la gestión técnica y financiera es asumida por una empresa que arrienda campos y terceriza las labores productivas por medio de contratistas de servicios, para lo cual suele apelar a financiamiento de terceros.

${ }^{3}$ La instalación de la categoría vino acompañada de la progresiva institucionalización de la problemática a nivel del Estado y de la definición de politicas especificamente orientadas al sector en el marco del Mercosur, en consonancia con lo que venía haciendo Brasil (Soverna y Tsakoumagkos, 2008)

territarias 30

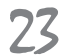


${ }^{4}$ Aunque las explotaciones de menos de 200 hectáreas disminuyeron un $50 \%$ en el periodo 1988-2002, el $80 \%$ de las explotaciones del partido se ubicaban en este estrato en el año 2002.

\section{territarias 30}

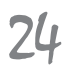

este sentido, una pregunta central que se puede plantear es si ocupa espacios 'vacíos', compite con otras formas agrarias - reemplazándolas y desplazándolas- (Reboratti, 1990), o bien existe una mera coexistencia. Podemos agregar a este interrogante otro vinculado a las conductas que adoptan los agentes afectados por estos procesos. Más específicamente si incorporan los rasgos del modelo que se delinea como hegemónico, abandonan su condición de productores directos o despliegan comportamientos resistenciales en los planos material y organizativo.

Los espacios locales cobran interés en este contexto ya que se convierten, en muchos casos, en campos de disputa por la presencia de diferentes modelos productivos. Desde esta perspectiva se analiza un partido de la región pampeana - el partido de San Pedro- donde tradicionalmente se han desarrollado producciones trabajointensivas orientadas al mercado interno (fruticultura y horticultura) con participación de productores familiares. Estas actividades son atípicas para lo que constituye la base productiva tradicional de la región - granos y ganadería bovina-. De hecho, la existencia de actividades intensivas y la elevada subdivisión de la tierra incidieron para que San Pedro presentara proporciones más elevadas en la cantidad de puestos de trabajo por explotación, comparándolo con otros partidos cercanos (Municipalidad de San Pedro, 2003). Al mismo tiempo, el peso de las explotaciones de menor tamaño dentro del total ${ }^{4}$ y el hecho de que la mano de obra en poco más de la mitad de ellas sea la del productor y su familia, constituyen indicadores de la relevancia de las explotaciones familiares en el área.

Con este punto de partida se propone entonces identificar los aspectos donde se expresan tensiones entre distintas producciones y formas de llevar a cabo la actividad, así como las respuestas generadas por los actores en el plano material y discursivo. Desde el punto de vista metodológico se apela al análisis de material cualitativo (documentos, noticias periodísticas y entrevistas en profundidad a productores y empresas, técnicos y representantes de diferentes organizaciones locales), complementado con la consideración de estadísticas provenientes de diversas fuentes.

\section{San Pedro como espacio productivo}

El partido de San Pedro, ubicado en el noreste de la provincia de Buenos Aires (mapa 1), posee una superficie de 132200 hectáreas de las cuales el $80 \%$ se dedicaba a la actividad agropecuaria en 2002. La construcción de este espacio geográfico obedeció a una conjunción de factores físicos, económicos y culturales, que dieron lugar a un paisaje rural diversificado, con presencia de fruticultura (cítricos y duraznos) horticultura (principalmente batata), producción de granos (cereales y oleaginosas) y ganadería bovina.

Sin embargo, esta situación se ha ido modificando con el paso del tiempo debido al avance de la agricultura extensiva. El fuerte crecimiento de la superficie implantada con soja contrasta con la tendencia 
Mapa 1. Área de estudio: Ubicación de San Pedro

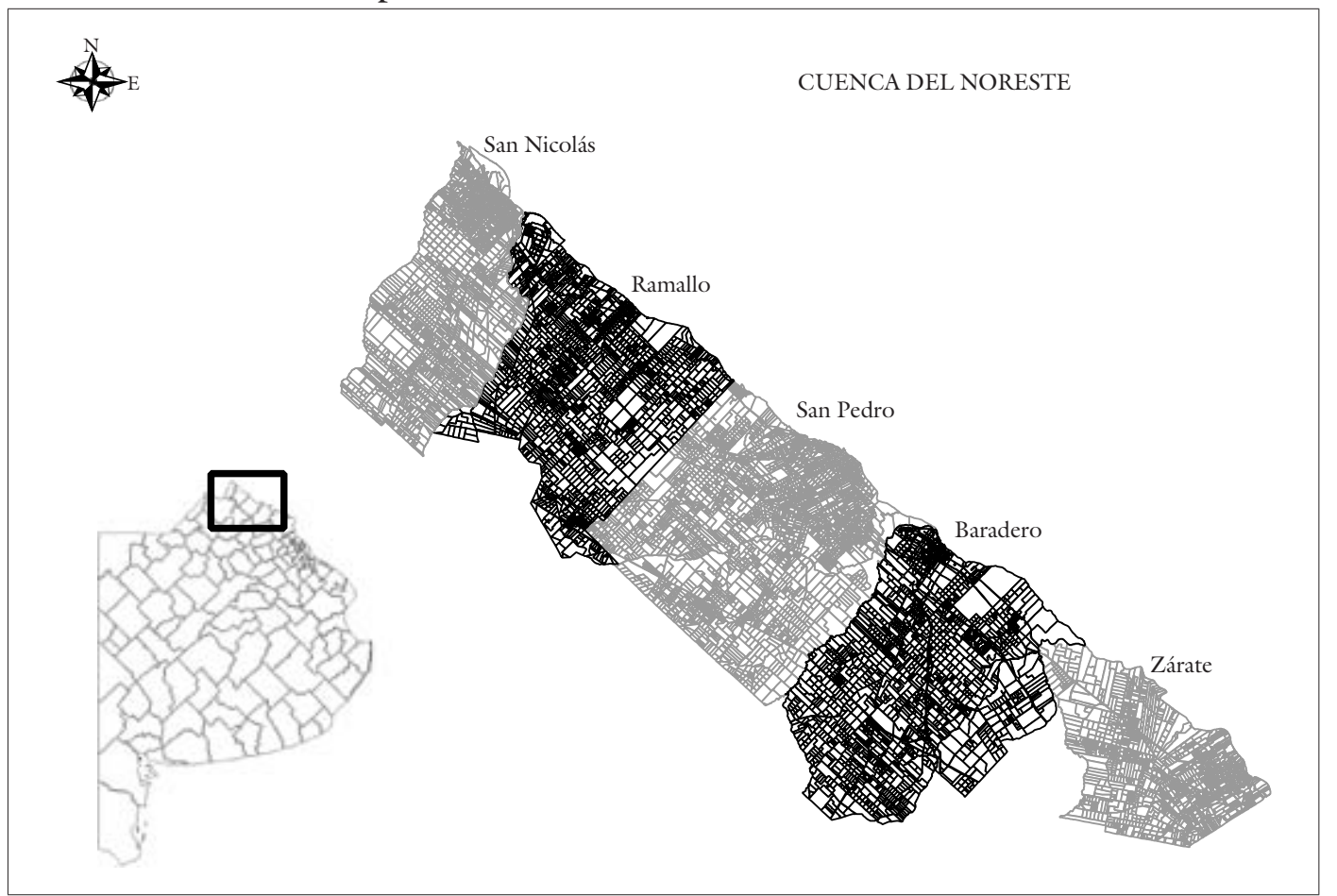

Fuente: Elaboración propia sobre la base de cartografía digital de ARBA.

decreciente de la superficie con frutales, proceso especialmente perceptible a partir de 2002. Ya en ese año, la oleaginosa, con 38133 hectáreas, representó el $48 \%$ de la superficie implantada del partido, mientras que los frutales, con 8616 hectáreas, equivalían al $12 \%$ del total. Actualmente, el Instituto Nacional de Tecnología Agropecuaria estima que solo persisten 4674 hectáreas dedicadas a la producción de naranja y durazno.

El proceso de retracción de la fruticultura es de causalidad múltiple. Engloba tanto cuestiones climáticas que afectaron a la actividad frutícola local como sus diferencias con respecto a otras zonas productoras del país, que presentarían mayor competitividad en términos relativos. A ello se agrega la desfavorable política económica, que durante ciertos períodos desalentó las exportaciones ${ }^{5}$ y factores de más largo plazo, como la tendencia declinante del consumo de fruta en el mercado interno.

En este contexto entran a jugar en el espacio analizado ciertas 'potencialidades' de la producción sojera en comparación con la fruticultura. El cultivo de soja posee menores riesgos climáticos y de mer-
${ }^{5}$ Merece señalarse al respecto que la politica de convertibilidad monetaria ( $1 \$=1$ us\$) adoptada durante la década del noventa dificultó las exportaciones de citricos, lo que favoreció la importación de fruta que competía en un mercado interno cada vez más deprimido. El cambio de política económica implementado en 2002 permitió recomponer la actividad exportadora, pero el paulatino incremento de los costos internos, no compensados por los precios obtenidos en los mercados internacionales, fue configurando una situación critica para la actividad, agravada porfenómenos climáticos adversos a nivel local.

territarias 30 25 
cado - al estar exitosamente inserto en circuitos globales-, se basa en un paquete tecnológico estandarizado (soja transgénica en combinación con siembra directa y herbicida glifosato) y demanda escasas labores, totalmente mecanizadas, que se pueden llevar a cabo mediante esquemas de tercerización. Por otra parte, sus tiempos productivos (seis meses) y la flexibilidad de comercialización que otorga la posibilidad de guardar el grano en silobolsas posibilitan una agricultura 'rápida', de características casi financieras, que contrastan con los años requeridos para la entrada en producción y recuperación de la inversión de cultivos perennes como los frutales.

A pesar de ello, el repliegue de la fruticultura varía en función de la combinación preexistente de rasgos sociales, culturales y geográficos que implican diferentes formas de apropiación del espacio rural, aún al interior del mismo partido. En el área occidental, donde las parcelas son de mayor extensión, la actividad frutícola prácticamente ha desaparecido. En cambio, el espacio más cercano al río Paraná, de parcelas más chicas, evidencia mutaciones en progreso, así como tensiones no resueltas entre la agricultura extensiva y otras formas de producir y ocupar el espacio rural (que incluyen, además de actividades intensivas como la fruticultura, usos no agropecuarios del suelo facilitados por la cercanía del partido a la ciudad de Buenos Aires).

Acompañando el proceso de disminución de superficie frutícola, el número de unidades en esta actividad se redujo en un $58 \%$ en el período $2002-2008$, siendo la caída más pronunciada en las más pequeñas (Pagliaricci, 2011). También ha bajado la cantidad de puestos de trabajo en el sector agropecuario, por cuanto la alta demanda de mano de obra estacional que genera la fruticultura ( 80 jornales $/$ ha/ año en frutales de carozo y 60 en cítricos) es muy superior al requerimiento de la agricultura de granos (medio jornal/ha/año) (INTA, 2008).

Las representaciones de los actores locales entrevistados conectan la disminución de la mano de obra en el sector agrario con diferentes problemáticas: la constitución de pueblos 'fantasma', la pérdida de la 'cultura' del trabajo, el incremento de la inseguridad, la mendicidad, los robos. También identifican las derivaciones paradojales de la expansión del cultivo de soja: mayores ingresos, pero desigualmente distribuidos.

[La soja] trae beneficios comerciales, sí. Porque hay un cierto poder adquisitivo, ‘adónde va? Quizás va a... concesionarios de autos, a herramientas de campo, estaciones de servicios, inmobiliarias. Ahora, a toda la ciudad le trae problemas. Porque ciudades que quizá por su producto bruto sean millonarias, después tienen toda la gente sin trabajo. ¿Sabés lo que vemos nosotros? Como que, para mucha gente es beneficio... pero lo que vemos nosotros que al tener menos mano de obra en San Pedro, hay una diferencia muy grande... de nivel de gente (referente del Centro de Comercio e Industria, 2011).

Con relación a la estructura agraria, la expansión de la soja vino acompañada 
de la presencia en la zona de pools de siembra y empresas productoras de semillas de origen extralocal. Algunos actores locales participan de esta dinámica, como es el caso de productores que han aumentado la superficie trabajada con base en el arriendo de tierras, o el segmento de contratistas de servicios que posee maquinaria moderna y presta servicios de siembra, fumigación y cosecha de granos (Craviotti y Palacios, 2011). Sin embargo, el avance de la soja incide en términos generales sobre la fruticultura local y, en particular, sobre los productores familiares de menor tamaño, debido al incremento de los cánones de arrendamiento de la tierra, que además se pactan en valores equivalentes a quintales de soja por hectárea, independientemente de la actividad desarrollada.

Todo está muy 'sojasizado'... Entonces, en quintales de soja, uno tiene que ofertar más o menos lo que pagan los que ponen soja. Si no, quedamos fuera del circuito. Aunque nos cuesta más, porque ellos... lo pueden, lo pueden esperar, guardar en silos (....) Nosotros, donde esto está, o lo vendemos o lo perdemos. (....) Entonces, es más difícil seguir ese ritmo, esta gente da valores de dólar, bueno, es otra cosa, el valor de cereal con lo que nosotros hacemos (Productor frutícola de 95 hectáreas con empaque, 2011)

Antes se arrendaba a un tanto por ciento, 25 o $30 \%$, vos cosechabas la fruta, el $30 \%$ era del dueño de la tierra. Se vendía en el campo, o cuando lo vendíamos le daba... era muy familiar. Hoy no. [Es] lo mismo que si hago soja. [Pago entre 15 y 17 quintales] Cuan- do realmente... si fuera realmente a lo que da un durazno, con el gasto que tenés, no podés pagar más de 8 o 10 quintales. Y estamos pagando eso para no perder el monte, porque si no, tenemos que cerrar el empaque (Empacador frutícola sin superficie propia)

Se han creado un puñado de empresas locales, muy grandes, muy agresivas para con el resto de los productores, en el sentido de la disputa por la tierra (...) Son productores, sí, sí, que tal vez, en 2003 estuvieron cosechando 500 o 600 hectáreas propias, compraron máquinas, compraron cosechadoras, tal vez han conseguido plata de afuera (...), y salieron a alquilar tres o cuatro mil hectáreas, pagando tal vez dos quintales más de lo que usualmente se paga (referente local de Federación Agraria en 2011).

Como surge de los testimonios previos, cambian las relaciones entre propietarios y arrendatarios por la presencia en la zona de agentes de mayor capacidad financiera. Los arreglos a porcentaje de lo cosechado han perdido vigencia, siendo reemplazados por otros basados en cánones fijos de arrendamiento en los cuales parte o la totalidad del monto acordado debe ser pagado por adelantado. En alguna medida, esto ha llevado a un proceso de recambio de los antiguos arrendatarios por otros que impulsan o están en condiciones de adaptarse a estos nuevos arreglos.

Podemos inclusive plantear la hipótesis de que la competencia entre modelos productivos diferentes, uno basado en la agricultura extensiva 'deslocalizada' y otro más incluyente, donde cobran importancia tersitarios 30 
los encadenamientos productivos locales, conduce a algunos productores frutícolas (especialmente los de mayor tamaño) a replicar en su actividad algunos rasgos del modelo sojero, fundamentalmente la orientación hacia circuitos globales y hacia el uso de tecnologías que permitan un incremento sostenido de la productividad. Así procuran insertarse en la exportación de naranjas en contraestación con base a la modernización de sus estructuras productivas y comerciales. Esto se expresa en la intensificación del uso de insumos (pulverizaciones con productos químicos y adopción de prácticas de fertirriego localizado) y en la mayor densidad de plantación por hectárea, así como en la búsqueda de arreglos directos con empresas comercializadoras en el exterior.

Sin embargo, ciertas peculiaridades de la fruticultura impiden la replicación automática y sin mediaciones de ciertos rasgos del modelo productivo representado por la soja: sea en el caso de la naranja como del durazno, se trata de producciones de ciclo largo que no habilitan una gestión orientada a la búsqueda de beneficios comerciales de corto plazo; de allí que no susciten particular interés de parte del sector financiero, que las ve como inversiones de riesgo. Debido al carácter perenne de estos cultivos y la necesidad de su supervisión constante existen limitaciones para aligerar la inversión en capitales fijos y tercerizar las actividades culturales. A diferencia de la soja, en este caso no existen paquetes tecnológicos 'cerrados', articulados en torno a desarrollos biotecnológicos.
En el caso de los fruticultores familiares, los comportamientos desplegados son heterogéneos. Mientras algunos incorporan prácticas que les permitan insertarse en el circuito de exportación de frutas, otros despliegan prácticas consistentes en el ahorro de gastos monetarios, la obtención de recursos mediante circuitos no mercantiles y la intensificación del trabajo familiar (Craviotti y Palacios, 2013a). Un aspecto común es la preservación e inclusive el fortalecimiento de la diversificación productiva. En ese marco, varios de ellos han incorporado la soja y otros cultivos anuales que les permiten complementar los ingresos obtenidos de la fruticultura. Así nos lo explicaba la esposa de un productor de 60 hectáreas que también hace soja "Nosotros apuntamos a eso, a la producción frutícola. La soja no nos interesa. Es algo para sacar el fondo, para poder seguir subsistiendo" (Entrevista personal, 19 de mayo de 2011). Quienes han encarado este camino han levantado los montes de fruta más antiguos y con variedades de poco valor comercial e incorporado la soja dentro de un esquema de rotación con el cultivo de batata o de manera coyuntural, previo a la implantación de nuevos montes frutales (principalmente durazno).

Algunos, no obstante, han dejado de lado esta producción debido a los aumentos de costos y los requerimientos fiscales involucrados, entre otros aspectos. Es más, una reconversión total hacia la soja es resistida por este tipo de productor, no solo por cuestiones de escala, sino también identitarias (Craviotti y Palacios, 2011). 
La soja te rinde si tenés muchas hectáreas, si tenés pocas no. Por eso nosotros tenemos alternativas, hay cítricos, durazno, soja y batata, durante todo el año (esposa de productor de 12 hectáreas de fruta que también hace soja). No, no lo arranqué [el monte frutícola]. No, porque lo hice, lo hice de chiquito... y todo el que tiene el monte ha pasado lo mismo que yo. Les cuesta muchísimo arrancarlo (productor con 15 hectáreas de fruta).

En otros casos, en cambio, la reconversión hacia el cultivo es más marcada y aceptada como la vía para sostenerse y crecer.

Dentro de este panorama, existe actualmente en la fruticultura una heterogeneidad de agentes (Craviotti y Palacios, 2013b). Los productores familiares se caracterizan por el involucramiento del productor y su familia en las tareas productivas y de gestión. Ahora bien, mientras una parte de ellos solo contrata jornales en momentos clave del ciclo productivo (poda y cosecha), por lo general vende la fruta sin cosechar y eventualmente parte de ella en mercados locales, existe un grupo de productores de tipo familiar-empresarial que emplea entre uno y tres trabajadores permanentes y en la mayoría de los casos integra el eslabón de empaque, que le permite acondicionar y vender la fruta en mercados mayoristas. Este grupo, mayoritario dentro del total de productores, en muchos casos destina parte de su fruta a la exportación, para lo cual realiza un conjunto de cuidados al monte frutal.

Otro tipo de situación es representada por los productores empresariales que or- ganizan la unidad productiva recurriendo solamente a mano de obra asalariada. Dentro de este grupo existen grandes empresas verticalmente integradas que emplean un número elevado de trabajadores y disponen de galpones de empaque acreditados para exportar. Además de disponer de plantaciones propias y arrendar campos de terceros con este propósito, compran fruta a otros productores (inclusive de otras zonas del país). Algunas de ellas también prestan servicios de empaque para exportación.

Este grupo, al controlar todas las fases de la cadena, impone sus condiciones a los productores a los que compra fruta, que varían según los vaivenes del mercado, por lo que la fase primaria se convierte en la variable de ajuste del sistema. La capacidad de articular intereses para formular demandas y una propuesta de desarrollo agrario es también mayor en las empresas verticalmente integradas, como veremos en el siguiente apartado.

\section{Los proyectos de los actores locales y sus implicancias}

En la zona analizada se observa la movilización de los actores locales en torno a un proyecto colectivamente construido. Resulta por tanto de interés analizar las características de la red de actores que apunta a revertir la retracción de la fruticultura así como sus núcleos discursivos; es decir, cuáles cuestiones son enfatizadas, cuáles excluidas y cuáles - de estar presentescobran un lugar secundario. territarios 30

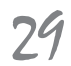


${ }^{6}$ Convenio Iascav-Ministerio de la Producción de la Provincia de Buenos Aires, donde el organismo nacional delegó en la provincia la responsabilidad del control de la calidad comercial y fitosanitaria de los citricos de la cuenca bonaerense que se exportaban a la (en ese entonces) Comunidad Económica Europea. La Comisión fue también reconocida por el gobierno provincial para integrar la Comisión 8 del Mercosur en representación de la República Argentina para el tratamiento del arancelamiento de la fruta de carozo (Mesa InterSectorial, 2009)

${ }^{7}$ Esta iniciativa apuntó a dar apoyo logístico a las exportaciones frutiborticolas de San Pedro (asesoramiento, bases de datos, comercialización, marketing, estudios de mercado, etc.), basándose en el modelo de la Fundación Pro-Chile. Contó con aval político y adhesión de productores, articulando con diversas organizaciones locales (Barsky, 2003).

${ }^{8}$ De esta forma, para la entrega del subsidio, los productores fueron divididos en tres categorias: los que poseían hasta 50 hectáreas se comprometian a tomar 6,5 jornales por hectárea, de los que el subsidio cubriría

\section{territarias 30}

El soporte de tal proyecto es la Mesa Multisectorial Agropecuaria que integran diversas organizaciones privadas - representativas de productores, trabajadores y asesores técnicos - junto con entidades estatales de la zona - el municipio y la Estación Experimental San Pedro del Instituto Nacional de Tecnología Agropecuaria-. Ante la visión de que la magnitud del problema planteado, la crisis de la fruticultura, excede los recursos de los gobiernos municipales, el interlocutor es el Estado provincial y, agotada esta instancia, el Nacional. Como metodología de trabajo, la Mesa privilegia la negociación por sobre la confrontación y la realización de propuestas en conjunto, que les abre más puertas $\mathrm{y}$, además, supone un freno para eventuales acciones oportunistas de algunos actores en desmedro de otros.

Se pueden rastrear antecedentes tenues de esta organización multiactoral en la primera mitad de los años noventa, cuando se conformó una comisión frutícola que procuró establecer instancias de control local en cuestiones relativas a la exportación de la fruta, ${ }^{6}$ y en la Fundación Pro-Sur, que encaró diversas acciones para reposicionar esta producción con vistas a la exportación. ${ }^{7}$ Este sesgo pro exportador es también visible en iniciativas políticas posteriores, que se tradujeron en planes de apoyo a la fruticultura de la zona.

El primero de los planes orientados hacia el sector, Caminos a la Producción, se puso en marcha en 1999, y consistió en un préstamo para ser utilizado en la contratación de mano de obra en la producción de duraznos. El Plan de Reactivación Frutícola implementado en 2003 fue en cambio más abarcador: financió tanto insumos como maquinaria y mano de obra para cítricos y frutales de carozo, con el objetivo de incrementar los volúmenes de exportación. Estaba destinado originariamente a pequeños productores según lo requerido desde el gobierno provincial, pero finalmente la Comisión Local priorizó la incorporación de pequeñas y medianas empresas, por considerarlas representativas del tipo de productor frutícola más difundido en el partido de San Pedro y por el efecto que tendría sobre el empleo su reactivación. El $30 \%$ de los productores habría accedido al crédito, con un impacto mayor en términos de superficie (Neiman et al, 2005). Además se hizo hincapié en el asociativismo, ya que los beneficiarios debían presentar proyectos grupales con el asesoramiento y seguimiento de un técnico.

La Mesa Multisectorial gestionó y obtuvo un nuevo apoyo provincial cuando se produjo una sequía en el año 2008. En este caso se les subsidió a los productores frutícolas la contratación de trabajadores. Se planteó una estratificación de los productores, previéndose un apoyo superior a los de menor superficie. ${ }^{8}$ Pero lo cierto es que de los 100 productores inscriptos, solo 42 cumplieron con los requisitos exigidos, y 9 de ellos recibieron la mitad de los fondos otorgados.

A esto le siguió un programa InterZafra (consistente en un nuevo subsidio para los trabajadores) y un financiamiento no reembolsable para los productores, que 
fue canalizado hacia fines del 2011 . En este caso, y a pedido del gobierno provincial, se estableció un tope para las grandes empresas y un aporte proporcionalmente mayor para los productores más pequeños.

En el recorrido temporal atravesado por la Mesa Multisectorial las sucesivas coyunturas trajeron consigo cambios en el diagnóstico y las propuestas, así como ajustes a los requerimientos planteados por sus interlocutores (funcionarios de diferentes áreas del Estado nacional y provincial). Las últimas iniciativas apuntan a fortalecer una estructura agraria de características más incluyentes. Así nos lo indica la siguiente reflexión, a cargo de uno de los técnicos privados que integran dicho entramado:

Nosotros pensamos en un momento, por ejemplo, en la forma asociativa, mucho, $y$ al productor no le gusta la forma asociativa. (...) Cambiamos bastante también la visión en cuanto a que en algún momento pensábamos en la necesidad de hacer grandes estructuras. Hoy creemos que no es necesario tener grandes estructuras (...) Porque las grandes estructuras generan turnos. ¿Cuál cosechamos primero? (...) A mí cuanto más, digamos, gente que se dedique a hacer cosecha haya, cuantos más galpones [de empaque] que sirvan para trabajar, aunque no sea para trabajar la fruta definitivamente para la exportación... En el primer subsidio dejamos afuera a todos los chiquitos, no nos dimos cuenta (...) Pedíamos que todos trajeran jornales y los productores chicos que se inscribieron no pudieron demostrar que ellos sacaban jornales (entrevista, abril de 2011).
Por otra parte y considerándolas en conjunto, lo que las distintas medidas presentan en común es el apoyo a la contratación de mano de obra. Esto se corresponde con la percepción de los actores que conforman la Mesa en cuanto a que este constituye el principal problema que genera la retracción de la fruticultura a nivel local. ${ }^{9}$ En contraste, los efectos sobre la estructura agraria y el paisaje rural generados por el reemplazo de los montes frutícolas por el cultivo de granos - la agricultura 'a escala' y la consiguiente disminución de las explotaciones familiares - adquieren una importancia menor, según se desprende de las entrevistas efectuadas a representantes de las organizaciones locales:

Y hoy quedan... cuatro o cinco mil hectáreas [de fruticultura] y tenemos 60000 habitantes. Eso realmente genera un impacto social, bastante complicado, ¿no es cierto? No lo perjudica a aquel que ha tenido su producción familiar que sigue sosteniéndose con eso... que eso es lo que ha venido haciendo durante toda la vida (referente local de la organización de trabajadores Uatre, entrevista personal, 20 de marzo de 2011).

Hay unos cuantos miles [de trabajadores] que se les complicó la vida porque ya no estaba más ese trabajo que iban escalonando, ¿no? En verano el durazno, después tenías la batata, después tenías la cítrica en invierno, en definitiva no trabajabas los doce meses, pero nueve o diez meses del año trabajabas, con buenos jornales, mucha gente quedó afuera de eso porque no hay trabajo... Y bueno, después en menor medida el productor el total; los de de 50 a 100 bectáreas emplearian 5,5 jornales por hectárea y gozarian del $80 \%$ de cobertura; los de 101 en adelante, 5 jornales por hectárea, de los que el subsidio les pagaria el $70 \%$ del total.

${ }^{9}$ Sin desconocer su importancia, esta situación se habría visto en parte compensada en el caso de los trabajadores de empaque por la estrategia adoptada por las empresas medianas y grandes de aprovisionarse de fruta no solo en San Pedro, sino también en otras zonas del pais, procesándola en los galpones de empaque ubicados en dicho partido.

territarias 30

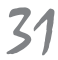


que dejó esa actividad, que en los ochenta era floreciente, rentable, aquél que tenía monte era un tipo que estaba bien, eh... y que tuvo que dejar la actividad, o la sigue con rentabilidad muy escasa, o con muy malos años. Lo que pasa que probablemente ese productor sigue siendo dueño de un campo que vale 10000 dólares la hectárea, ¿no? Entonces, desde el punto de vista del capital que tiene está lejos de ser un pobre, pero el ingreso que obtiene por ese campo, le permite vivir ahí nomás (referente local de FAA, entrevista personal, 20 de marzo de 2011 ).

Por otro lado, los actores locales participantes de la Mesa Multisectorial perciben que los apoyos canalizados hacia la fruticultura constituyen acciones parciales que no atacan las causas estructurales de su retracción. Por ello gestionan la puesta en marcha de una política de mayor envergadura, cuya implementación sea controlada localmente. La propuesta en cuestión, denominada Plan para la revalorización y fortalecimiento de la cuenca fruticola del noreste bonaerense (2009) da cuenta de la construcción de marcos culturales y de una identidad colectiva (cuenca frutícola) que incluye a otros partidos cercanos donde se ha desarrollado la actividad.

El mencionado plan contempla distintas etapas, con subsidios para mano de obra en el corto y mediano plazo, y créditos para inversiones a tasa subsidiada en plazos más largos, acordes con la evolución de cultivos de carácter perenne. Apunta a una fruticultura "direccionada y tecnificada a full, con variedades adecuadas, riego localizado, sis- temas de defensa contra heladas" (técnico privado participante de la Mesa, 2011). Se argumenta que si bien la exportación ha incrementado su relevancia, convirtiéndose en el eje sobre el que se basa la rentabilidad de las empresas frutícolas, el objetivo no es solo consolidarla sino también acceder a mercados nacionales hoy vedados por la existencia de barreras sanitarias. Así pues, el énfasis "está puesto en tener una mercadería que pueda llegar a cualquiera de los lugares que se nos ocurra. Porque vos no podés hacer algo hoy pensando nada más que en exportación, porque con este dólar quedamos todos afuera de carrera" (Técnico privado participante de la Mesa, entrevista personal, abril de 2011).

El Plan refleja los compromisos alcanzados y muestra el intento de recuperar la heterogeneidad de productores existente, si bien hace explícita su defensa de las estructuras de producción empresariales, en pie de igualdad con las unidades pequeñas basadas en el trabajo familiar:

La plurianualidad característica de la fruticultura genera una alta vulnerabilidad que, tanto factores estructurales como coyunturales, hacen que las inversiones se vean retraídas y espacios frutícolas sean reemplazados por cultivos agrícolas (...) Esta situación afecta de manera diferente a todos los participantes del sistema frutícola bonaerense, resultando más afectados los productores frutícolas independientes ubicados en los estratos inferiores. (...) el mayor peso porcentual se ubica en los estratos de menores superficies y que comprende a empresas familiares, que 
deben ser tenidas en cuenta no solo como unidad económica sino como modelo desde la diversidad de los actores del sistema. Esto no invalida que las empresas de mayor escala deban ser menos consideradas, ya que son estos actores aquellos que ocupan la mayor proporción de mano de obra de la población más vulnerable.

Algunos técnicos privados - cuyo rol ha sido destacado en la elaboración y gestión del Plan- consideran que la persistencia de las grandes empresas integradas es fundamental para la continuidad de los productores de menor tamaño, por diversas razones: "De repente te encontrás con que el productor grande que salía a comprar la producción no está... se te complica para venderla" (Técnico 1, entrevista personal, 3 de abril de 2011). "El productor grande hoy tiene una figura que es interesante, porque es el que está salvando muchos montes $(. .$.$) se ha convertido en arrenda-$ tario" (Técnico 2, entrevista personal, 3 de abril de 2011). Además, al acondicionar en sus empaques fruta proveniente de otras zonas del país ocupa más mano de obra local que los productores independientes. Por lo tanto, la necesidad de asegurar la continuidad de las grandes empresas integradas es legitimada en función de sus efectos directos e indirectos sobre otros agentes, en una elaboración discursiva que deja de lado las relaciones de subordinación que ligan a unos y otros. Es decir que dentro del proyecto local de revitalización de la fruticultura está ausente una propuesta de cómo hacer más viable la inserción de los agentes productivos más débiles, aquellos productores familiares que, al carecer de instalaciones de empaque y acceso directo a los mercados, venden su producción 'en planta', sin capacidad de negociar sus condiciones de venta.

Podemos acordar con Bourdieu y Wacquant (2005) en que la posición social y el acceso a distintas formas de capital son elementos fundamentales que inciden en las disposiciones culturales. De esta manera, afectan la percepción de un problema y la formulación de respuestas (Moruzzi, 2004). Lo cierto es que el carácter de la propuesta consensuada por los actores locales vinculados a la fruticultura responde a aquellos que adquieren mayor peso en esta iniciativa de coordinación: la cámara de los productores y empacadores - que en opinión de algunos de los entrevistados representa en mayor medida los intereses de las empresas verticalmente integradasasí como las organizaciones de los trabajadores de campo y empaque, en su mayoría insertos en este tipo de unidades. A diferencia de otros, estos actores han tenido continuidad en cuanto a su participación en esta instancia de articulación de intereses.

Así, parte de los productores frutícolas familiares no participa en estas iniciativas por el mismo desaliento que genera la evolución desfavorable de la actividad frutícola o por percibir sus intereses como diferentes a los de las empresas verticalmente integradas.

“Están los del empaque en la cámara también, son los productores y los de los territarias 30 
galpones. Y bueno... no es..., es decir, para mí tendrían que estar los productores nada más" (productor con 40 hectáreas de fruta, vende en planta, entrevista personal, 20 de mayo de 2011).

Yo personalmente lo que sentí es que...el pequeño productor, viste, nunca fue centro de atención verdaderamente como tal. Es decir, se le tuvo en cuenta a la hora de los reclamos... de sumar, para reclamar, pelear jornales. Pero siempre fueron significativos para el gran productor (...) Yo entiendo, quien maneja jornales, maneja un volumen más importante que... una firma como esta. Vos como pequeño productor no sé si tenés peso como para... no sos significativo para la economía (productor con ocho hectáreas de fruta, vende en planta, entrevista personal, 19 de mayo de 2011).

"Se ve que cuando viene algo, viene todo para los más grandes" (productor con seis hectáreas de fruta, entrevista personal, 19 de mayo de 2011).

\section{Reflexiones finales}

La consolidación de un modelo de desarrollo agrario incide en múltiples planos: en el tipo de producciones desarrolladas, en los perfiles de los agentes participantes, en las diferentes actividades - desde la explotación agraria hasta llegar al mercado-, en las relaciones que establecen entre sí y con otros sectores, en la dinámica y configuración de los espacios locales en los que se desenvuelven.

En el área analizada se identifica la ex-

\section{territarios 30} 34 pansión de la producción de soja destinada a abastecer los mercados mundiales, en parte como producto de ciertas cualidades que le son atribuidas y también por los factores propios de la evolución de otras actividades (como la fruticultura) que en una determinada etapa compiten por los usos del suelo.

Las consecuencias de esta expansión son una mayor homogeneización del espacio rural (aunque sigue siendo más diverso que otras áreas rurales pampeanas), la pérdida de puestos de trabajo y la disminución de las unidades productivas. Se verifica también el incremento del valor de la tierra y la pérdida de importancia de modalidades tradicionales de arriendo basadas en compartir resultados 'a cosecha', que afectan al conjunto de producciones desarrolladas en el medio rural, sean estas extensivas o intensivas.

Este proceso se da por el acceso a información, los vínculos personales entre los agentes que encaran diferentes actividades y aún por el carácter de sujetos 'híbridos' de algunos de ellos. Como consecuencia en las explotaciones frutícolas de mayor tamaño se afianzan ciertos rasgos habitualmente atribuidos al modelo de los agronegocios - la intensificación de la relación capital/ tierra y el uso de insumos industriales, la orientación hacia la exportación-. Pero no por ello se reproducen mecánicamente otros rasgos, básicamente una elevada flexibilidad productiva, organizacional y comercial.

Dejando de lado ciertas especificidades de la fruticultura comocultivo perenne, aspectos centrales como el grado de subdivisión de la tierra, la importancia de 
los productores familiares y la índole de sus comportamientos pueden representar posibles frenos para su expansión. En este sentido se destacan las formas en que este tipo de productores organizan sus recursos y procuran su mejor aprovechamiento, a fin de lograr la continuidad de sus unidades a lo largo de las generaciones.

Así hemos observado que productores de este tipo han logrado persistir en la actividad profundizando su diversificación, fundamentalmente combinando producciones perennes con cultivos anuales a fin de disminuir riesgos, complementar ingresos y lograr cierta continuidad de los mismos a lo largo del año. La soja puede aparecer en ciertos casos como parte de una lógica resistencial, que difiere de un mero replicamiento del denominado modelo de los agronegocios. No obstante ello, cierta debilidad de estos agentes como actores sociales para posicionar sus intereses en las propuestas de desarrollo constituye un indicador indirecto de sus dificultades para persistir dentro de la estructura agraria que se afirma.

En contraposición a esta situación, se destacan las habilidades sociales de otros actores para articular sus demandas e interactuar con otros actores públicos y privados (Fligstein, 2001). Así las empresas frutícolas verticalmente integradas y aquellos articulados a ellas han sido decisivos en la construcción de una identidad colectiva - la cuenca frutícola- y en el contenido adoptado por las propuestas formuladas.
Si bien estas últimas dan cuenta de una visión que trasciende el corto plazo y orientada hacia la defensa de los anclajes locales de la producción agraria, no logra trascender el ámbito estrictamente sectorial para abarcar el conjunto de actividades desarrolladas en el medio rural y los diversos actores allí presentes. Al igual que manifiestan el costado político, de alineación de intereses, de una actividad agroindustrial en un espacio determinado, donde algunos de ellos resultan minimizados o directamente excluidos.

\section{Referencias}

Balsa, J. (2006). El desvanecimiento del mundo chacarero. Transformaciones sociales en la agricultura bonaerense, 19371988. Bernal: Universidad Nacional de Quilmes.

Barsky, O. (1992). Explotaciones familiares en el agro pampeano: procesos, interpretaciones y políticas. En O. Barsky. Explotaciones familiares en el agro pampeano. Vol. I (pp. 7-42). Buenos Aires: Centro Editor de América Latina.

Barsky, A. (2003), La Pampa mallorquina. Estudio regional de un espacio productivo horticola del noreste bonaerense: San Pedro, provincia de Buenos Aires. Tesis de Maestría Facultad Latinoamericana de Ciencias Sociales, Buenos Aires.

Bisang, R. (2007). El desarrollo agropecuario en las últimas décadas: ¿volver a creer? En B. Kosakoff (Ed.), Crisis, recuperación y nuevas dilemas. La economía 


\section{territarias 30}

argentina 2002-2007 (pp. 187-260). Santiago de Chile: Cepal.

Bourdieu, P. y Wacquant, L. (2005). Una invitación a la sociología reflexiva. Buenos Aires: Siglo XXI Editores.

Craviotti, C. y Palacios, P. (2011). Y se fueron saliendo los montes: la fruticultura del noreste de la provincia de Buenos Aires y la dinámica del modelo agroalimentario. Ponencia presentada en VII Jornadas de Estudios Agrarios y Agroindustriales, Buenos Aires, Argentina.

Craviotti, C. y Palacios, P. (2013a). Estrategias de productores familiares en contextos socio-productivos adversos: La fruticultura familiar en el noreste de la provincia de Buenos Aires, Argentina. Trabajo y Sociedad, XVII(20), 259-279.

Craviotti, C. y Palacios, P. (2013b). Dinámicas de los territorios pampeanos: Producción fruticola y modalidades de articulación entre productores y empacadores en el noreste bonaerense. Ponencia presentada en las VIII Jornadas de Estudios Agrarios y Agroindustriales, Buenos Aires, Argentina.

Da Silva, J. G. (1994). Complejos agroindustriales y otros complejos. Agricultura y Sociedad, (72), 205-240.

Davis, J. y Goldberg. R. (1957). A Concept in Agribusiness. Boston: Graduate School of Business Administration, Harvard University.

Fligstein, N. (2001). Social Skill and the theory of fields. Sociological Theory, 19(2), 105-125.

Friedland. W. (2001). A Reprise on Commodity Systems Methodology. Internatio- nal. Journal of Sociology of Agriculture and Food, 9(1), 82-103.

Giarracca, N. (1990). El campesinado en la Argentina: Un debate tardío. Realidad Económica, (94), 54-65.

Gras, C. y Hernández V. (2009). La Argentina rural. De la agricultura familiar a los agronegocios. Buenos Aires: Editorial Biblos.

Heredia, B., Palmeira, M., Pereira Leite, S. (2010). Sociedade e economia do "agronegócio" no Brasil. RBCS, 25(74), 159-196.

Mançano Fernandez, B. (2004), Onovo nome é agribusiness. Recuperado de http:// www4.fct.unesp.br/nera/publicacoes/ Onomeeagribusiness.pdf

Mesa Multisectorial Agropecuaria (2009). Plan para la revalorización y fortalecimiento de la cuenca fruticola del noreste bonaerense (mimeo).

Mesa Multisectorial Agropecuaria (2010). Propuestas para las autoridades (mimeo).

Moruzzi, F. (2004). Concepciones concurrentes en torno de las politicas públicas de apoyo a la agricultura familiar: Una relectura sobre la construcción del Pronaf. Cuiabá: Anales XVII Congreso Sober.

Mundler, P. Jauneau, J. C., Guermonprez, B. y J. Pluvinage (2009), The sustainability of small dairy farms in six regions of France. The roles of resources and local institutions, 111 EAAE-IAEE Seminar "Small farms: Decline of persistence", University of Kent, Canterbury, 26 al 27 de junio. 
Municipalidad de San Pedro (2003). Plan Estratégico (mimeo).

Neiman, G., González, M., Quaranta, G., Bardomás, S., Blanco, M., Berger, M., Goldfarb, L., y Jiménez D. (2005). Análisis participativo del proceso de transformación productiva e institucional en el partido de San Pedro, provincia de Buenos Aires. Documento efectuado en el marco de la preparación de la Estrategia Nacional de Desarrollo Rural para la Argentina, Convenio sAgPya Programa Multidonante Gobierno de Italia-FIDA-BID.

Ordóñez, H. (2000). Nueva economía y negocios agroalimentarios. Buenos Aires: Universidad de Buenos Aires.

Pagliaricci, L. (2011). Cambios estructurales en la fruticultura de San Pedro. En Informe marzo 2011. Proyecto regional de desarrollo territorial, Sistema de información territorial, Instituto $\mathrm{Na}$ cional de Tecnología Agropecuaria, pp. 13-15.

Patrouilleau, R., Saavedra, M., Patroullieau, M. y Gauna, D. (2012). Escenarios del sistema agroalimentario argentino al 2020. Colección Cuadernos de prospectiva 2. Buenos Aires: Instituto Nacional de Tecnología Agropecuaria.

Programa de Agronegocios y Alimentos (PAA) (2009) ¿Qué son los agronegocios? Recuperado de https://sites.google. com/a/agro.uba.ar/newsletter-paa/ newsletter-5.

Reboratti, C. (1990). Agribusiness y reestructuración agraria en Argentina. En E. Laurelli y Lindemboim J. (comps.).
Reestructuración económica global (pp. 147-164). Buenos Aires: CEUR, Fundación Friedrich Ebert.

Reboratti, C. (2010). Un mar de soja: la nueva agricultura en Argentina y sus consecuencias. Revista de Geografía Norte Grande, (45), 63-76.

Schiavoni, G. (2010). Describir y prescribir: la tipificación de la agricultura familiar en Argentina. En M. Manzanal y G. Neiman (comps.) Las agriculturas familiares del Mercosur. Trayectorias, amenazas y desafíos (pp. 43-59). Buenos Aires: Ediciones Ciccus.

Soverna, S. \& Tsakoumagkos P. (agosto, 2008). Sobre el uso de trabajo asalariado en las explotaciones familiares. Documento presentado en el Taller de Discusión sobre la Agricultura Familiar Pampeana. Instituto de Investigación y Desarrollo Tecnológico para la Pequeña Agricultura Familiar.

Teubal, M. (1999). Complejos y sistemas agroalimentarios. Aspectos téorico-metodológicos. En N. Giarracca (coord.). Estudios rurales. Teorias, problemas y estrategias metodológicas (pp. 97-121). Buenos Aires: La Colmena.

Tsakoumagkos, P. (1987). Sobre el campesinado en Argentina. Revista Argentina de Economia Agraria, I(II), 229269.

Vértiz, P. (2013). El avance de los agronegocios sobre regiones marginales: el caso de Chascomus y Lezama. Ponencia presentada en VIII Jornadas de Estudios Agrarios y Agroindustriales, Buenos Aires, Argentina. territarias 30 
Wilkinson, J. (2008). Mercados, redes e valores. Porto Alegre: UfRGS Editora.

\section{Fuentes estadísticas}

Indec, Censos Nacionales Agropecuarios de 1988 y 2002; Censo de Población 2001.
INTA, Censo Frutícola de San Pedro, 2002. INTA, Relevamiento aerofotográfico, 2010.

Ministerio de Agricultura, Ganadería y Pesca de la Nación, Estimaciones agrícolas $1977 / 78,1989 / 81 ; 1987 / 88$, $2006 / 7,2009 / 10$ 